\title{
Epidemiology of Breast Cancer among Females in Basrah
}

\author{
Omran S Habib ${ }^{1 *}$, Lamis A Hameed ${ }^{1}$, Narjis AAjeel ${ }^{1}$, Mazin H Al-Hawaz ${ }^{2}$, Zaki \\ A Al-Faddagh ${ }^{2}$, Ghalib N Nasr ${ }^{3}$, Ali H Al-Sodani ${ }^{4}$, Asaad A Khalaf ${ }^{4}$, Hasson M \\ Hasson $^{4}$, Aida A Abdul-Samad ${ }^{4}$
}

\begin{abstract}
Breast cancer is the most frequent cancer in females. Its incidence is higher in developed countries than in developing ones partly due to variation in risk exposure and partly due to better detection methods. Scattered evidence in Basrah, Iraq, suggests that breast cancer has been increasing at a significant pace in recent years. This study aimed to measure the current level of risk of breast cancer among females in Basrah and to describe the time trend over almost a decade of years. Data on breast cancer cases from all sources of cancer registration in Basrah governorate were compiled for the years 2005-2012. The data for each year were first checked separately for duplicate reporting of cases among various sources. Then the eight files were pooled together and checked again for any duplicate cases among years of registration. The final set of data contained 2,284 cases of breast cancer (2,213 female cases and 71 male cases). All patients were inhabitants of Basrah governorate at the time of diagnosis. Figures on the Basrah population were obtained from various sources including the Ministry of Health, Ministry of Planning and Developmental Collaboration and local household surveys. It was possible to have total population estimates for each year and by age and sex. The data were imported into SPSS (version 17) software. Age specific and year specific incidence rates were calculated. The age standardized incidence rate was also calculated using world population as the standard population to be 34.9 per 100,000 females. Age-wise, no case was reported among children aged less than 15 years and the incidence increased with advancing age reaching a peak of 123.8/100,000 females at the age range of 50-54 years. The time trend of the crude incidence rate showed only modest increased risk with passage of years and no age shift could be documented in this study. Breast cancer in females in Basrah is a significant health problem. The current incidence rate (crude, 23.7/100,000, age-standardized, 34.9/100,000) is high and justifies intensive efforts to improve early detection of cases, provide better treatment amenities and introduce long term preventive measures. Using the age standardized incidence rate as reported in this paper, it is possible to put the risk in Basrah within a regional and international context.
\end{abstract}

Keywords: Breast cancer - age standarized incidence - time trend - Basrah

Asian Pac J Cancer Prev, 17, Cancer Control in Western Asia Special Issue, 191-195

\section{Introduction}

Breast cancer is the most frequent cancer in females. Its incidence is higher in developed countries than in developing ones partly due to variation in risk exposure and partly due to better detection methods (Ferlay et al, 2013). Available evidence in Basrah suggests that breast cancer is increasing at a significant pace in recent years. (Habib etal., 2007, BCRG., 2009). For example, a hospital-based study reported an incidence rate of about 11/ 100,000 females (Al-Badri and Ajeel, 1998), but recent reports put the annual incidence rate among females at around 23 per 100,000 (BCRG 2009, Habib et al, 2010). However, complete data on incident cancer is only recently attepted through a combination of data of improved cancer registration (Habib et al., 2010) and household surveys (Al-Hilfi and Habib, 2015, Al-Hilfi and Habib., 2015 ).

The true extent of breast cancer in terms of incidence rate is still awaiting to be known. The exact magnitude of risk and determinants of such pattern are not well documented. Few small-scale studies have been carried out on this important cancer and attempted to shed light on extent and risk factors (Al-Badri and Ajeel, 1998, Abdul-Samad et al, 2009) given the significant share of this cancer among all cancers registered in Basrah (16.8\% of all cancers) and especially among females (30.2\% of female cancers) (BCRG, 2009). Such level puts Basrah

${ }^{1}$ Department of Community Medicine, ${ }^{2}$ Department of Surgery, College of Medicine, University of Basrah, ${ }^{4}$ Directorate General of Health Services, Basrah, Iraq, ${ }^{3}$ Azerbaijan Medical University, Baku, Azerbaijan.*For correspondence: omran49_basmed@ yahoo.com 
somewhere in the middle of neighboring countries (Tawarneh, 2007, Al-Hamdan, 2008). During the last ten years, extensive work was done by Basrah Cancer Research Group (BCRG) to obtain as accurate data as possible on all cancers in Basrah. The achievement so far is sufficient to make feasible the estimation of fairly accurate epidemiological parameters. There is a need to carry out at least four types of research on breast cancer: first is to document time trends with reasonable accuracy to quantify the change in risk (if any), second is a large scale case-control study to identify pattern of risk factors and locally acting determinants of the apparent rise in the incidence rate, and third, a five-year survival study to reflect on quality of care and fourth is a study on quality of life. In addition, research on new tools for diagnosis and prognosis such as the use of immunological parameters and others is also necessary (Farina and Mackay, 2014). This paper presents the most accurate data so far on breast cancer in Basrah governorate in terms of age, sex and time trend. It is hypothesized that the data used are accurate enough to answer specific research questions: What is the current level of risk of breast cancer among females in Basrah? Did the risk increase with time during the last years?

\section{Material and Methods}

In Basrah, people with cancer are mainly identified and their cancer is diagnosed when they visit specialist doctors in the private clinics, the consultancy clinics in major hospitals, and centres specialized to deal with cancer. Few cases may be detected in primary health care institutions. In each of the major hospitals, a cancer registration unit exists. These units report registered cases to the Cancer Control Centre (CCC) as the point of pooling of cases at Basrah governorate level. Cases which are treated in the oncolgy centres are also reported to the (CCC). In addition breast cancer early detection centres were established and they also report detected cases to the CCC. Further, a major source of cases is a histopathological cancer registration, which was established at the Department of Pathology and Forensic Medicine, College of Medicine, University of Basrah to compile and register solid tumours. Childhood cancers are mainly treated at the Children Specialized Hospital. All cases registered in all these registration units and centres are compiled and pooled in one epidemiological unit at the College of Medicine for checking and epidemiological analysis. A copy of the data is also sent to the Iraqi Cancer Board in Baghdad.

The cases which are registered in Basrah are drawn from the population of Basrah and adjacent governorates. From epidemiological point of view, cases can be identified and classified according to age, sex, place of residence, cancer site, histopathological typing, year of diagnosis and source where they first identified.

Data on breast cancer cases from all these sources were used in this study. Excel files were obtained for each of the eight years covered in the study (2005-2012). The data for each year were first checked separately for duplicate reporting of cases among various sources. Then the eight files were pooled together and checked again for any duplicate cases among years of registration. The final set of data contained 2,284 cases of breast cancer (2,213 female cases and 71 male cases). These were the cases from the inhabitants of Basrah governorate at the time of diagnosis.

Figures on Basrah population were obtained from various sources including Ministry of Health, Ministry of Planning and and Developmental Collaboration (MoP, 2013) and local household surveys. It was possible to have total population estimates for each year, by age and sex.

The data were imported into SPSS (Statistical Package for Social Sciences -version 17) software. Age specific and year specific incidence rates were calculated. The age standardized incidence rate was also calculated using World population as the standard population (Parkin et al, 2005).

\section{Results}

A total of 2,213 new cases of breast cancer were diagnosed, treated or registered in Basrah among females during the period 2005-2012 inclusive. These cases are all from the normal resident population in Basrah governorate at the time of diagnosis.

\section{Year of diagnosis}

Table 1 shows the distribution of new female breast cancer cases registered in Basrah during 2005-2012 by Age pattern of cases

The numbers, percentages and age specific incidence

Table 1. Estimates of Female Population, Numbers and Percentages of New Breast Cancer Cases and Annual Incidence Rates per 100,000 Females: Basrah 2005-2012.

\begin{tabular}{lcccr}
\hline Year of registration & Estimated female population & No. of new cases registered & $\%$ & IR/100,000 females \\
\hline 2005 & $1,053,638.0$ & 244.0 & 11.0 & 23.2 \\
2006 & $1,085,247.0$ & 226.0 & 10.2 & 20.8 \\
2007 & $1,117,805.0$ & 269.0 & 12.2 & 24.1 \\
2008 & $1,151,339.0$ & 286.0 & 12.9 & 24.8 \\
2009 & $1,185,879.0$ & 271.0 & 12.3 & 22.9 \\
2010 & $1,216,493.0$ & 30.0 & 13.6 & 24.7 \\
2011 & $1,248,275.0$ & 290.0 & 13.1 & 23.2 \\
2012 & $1,281,236.0$ & 326.0 & 14.7 & 25.4 \\
Total & $1,168,609.0$ & 2,2130 & 100.0 & 23.67 \\
\hline
\end{tabular}

192 Asian Pacific Journal of Cancer Prevention, Vol 17, Cancer Control in Western Asia Special Issue, 2016 
Table 2. Estimated Population, Number and Percentages of New Cases and Age-Specific Incidence Rates of Breast Cancer: Basrah, Females 2005-2012.

\begin{tabular}{|c|c|c|c|c|}
\hline Age in years + A15:E25 & Estimated mid-period female population & No. of cases in 5 years & $\%$ & IR/100,000 females \\
\hline$<5$ & $174,123.0$ & 0.0 & 0.0 & 0.0 \\
\hline September-05 & $161,268.0$ & 0.0 & 0.0 & 0.0 \\
\hline October-14 & $140,233.0$ & 0.0 & 0.0 & 0.0 \\
\hline $15-19$ & $119,198.0$ & 9.0 & 0.4 & 0.9 \\
\hline $20-24$ & $107,512.0$ & 24.0 & 1.1 & 2.8 \\
\hline $25-29$ & $91,152.0$ & 77.0 & 3.5 & 10.6 \\
\hline $30-34$ & $85,308.0$ & 125.0 & 5.6 & 18.3 \\
\hline $35-39$ & $73,622.0$ & 249.0 & 11.3 & 42.3 \\
\hline $40-44$ & $61,936.0$ & 376.0 & 17.0 & 75.9 \\
\hline $45-49$ & $43,239.0$ & 355.0 & 16.0 & 102.6 \\
\hline $50-54$ & $32,721.0$ & 324.0 & 14.6 & 123.8 \\
\hline $55-59$ & $24,541.0$ & 207.0 & 9.4 & 105.4 \\
\hline $60-64$ & $23,372.0$ & 207.0 & 9.4 & 110.7 \\
\hline $65-69$ & $12,855.0$ & 120.0 & 5.4 & 116.7 \\
\hline $70-74$ & $9,349.0$ & 79.0 & 3.6 & 105.6 \\
\hline 75 \&above & $8,180.0$ & 61.0 & 2.8 & 93.2 \\
\hline Total & $1,168,609.0$ & $2,213.0$ & 100.0 & 23.7 \\
\hline
\end{tabular}

Age standardized incidence rate $=34.9$ per 100,000 females

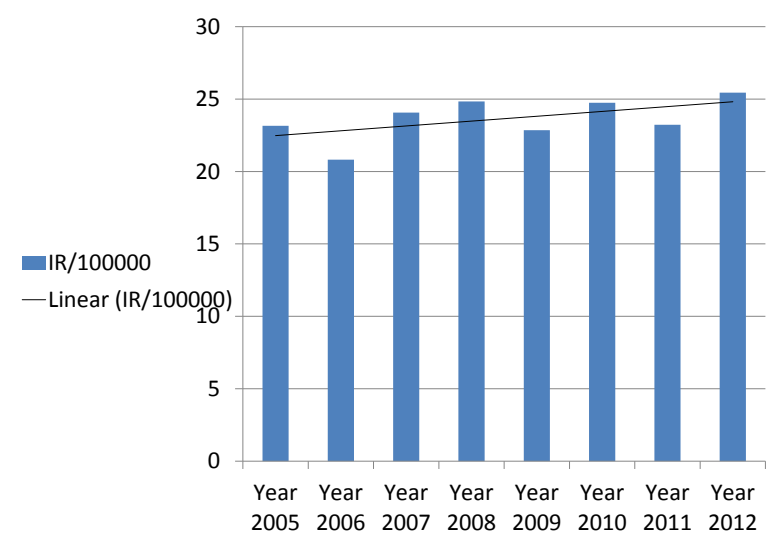

Figure 1. Year-specific IR per 100,000-Basrah 2005-2012

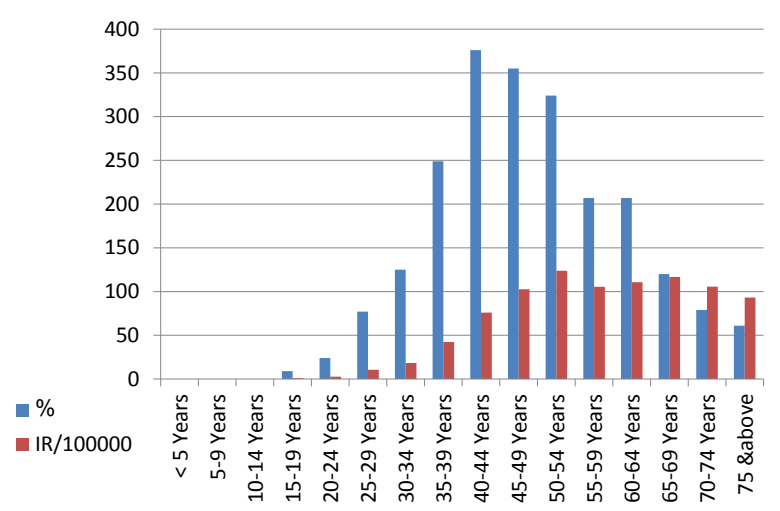

Figure 2. Relative Frequency and Age Specific Incidence Rate In Females: Basrah 2005-2012 ASIR=34.8/100,000
Table 3. Comparative Age-Standardized Incidence Rates of Breast Cancer in Selected Asian and European Countries.

\begin{tabular}{|c|c|}
\hline Country & $\begin{array}{l}\text { Age-standardized incidence } \\
\text { rate } / 100,000 \text { females* }\end{array}$ \\
\hline Saudi Arabia & 13.0 \\
\hline Iran & 23.1 \\
\hline India & 28.9 \\
\hline Turkey & 33.3 \\
\hline Qatar & 33.9 \\
\hline Basrah & 34.9 \\
\hline Japan & 35.1 \\
\hline Kuwait & 36.0 \\
\hline China & 36.2 \\
\hline Jordan & 42.5 \\
\hline Bahrain & 47.0 \\
\hline Poland & 53.7 \\
\hline United Kingdom & 74.4 \\
\hline Sweden & 76.6 \\
\hline Denmark & 81.3 \\
\hline United States of America & 89.5 \\
\hline \multicolumn{2}{|c|}{$\begin{array}{l}\text { * Source: Authors prepared based on references 1,9,10 19,20. } \\
\text { Most of the figures are related to the period 2000-2008 } \\
\text { the years they were first recognized as cases of cancer. } \\
\text { There is a slight tendency for the number of cases and } \\
\text { the relative frequency to increase with years. Looking for } \\
\text { the years they were first recognized as cases of cancer. } \\
\text { There is a slight tendency for the number of cases and the } \\
\text { relative frequency to increase with years. Looking for the } \\
\text { year-specific incidence rates (Table } 1 \text { and Figure 1), only } \\
\text { a slight rising time trend is noticed also. }\end{array}$} \\
\hline
\end{tabular}




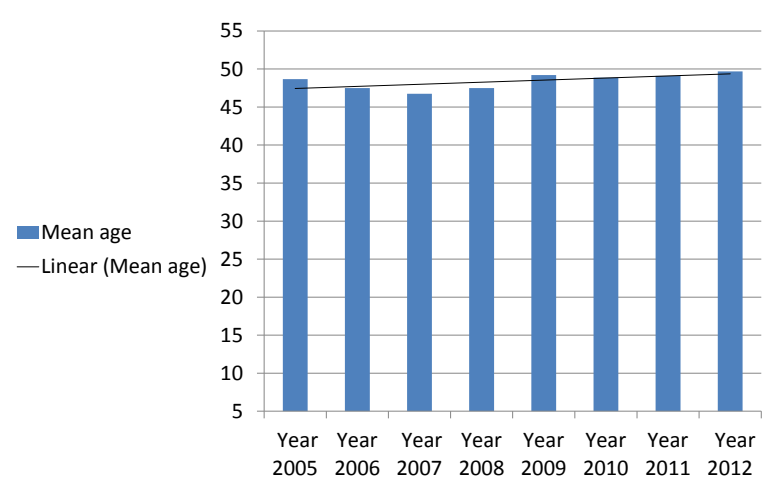

Figure 3. Mean Age of Incident Cases by Years: Basrah 2005-2012.

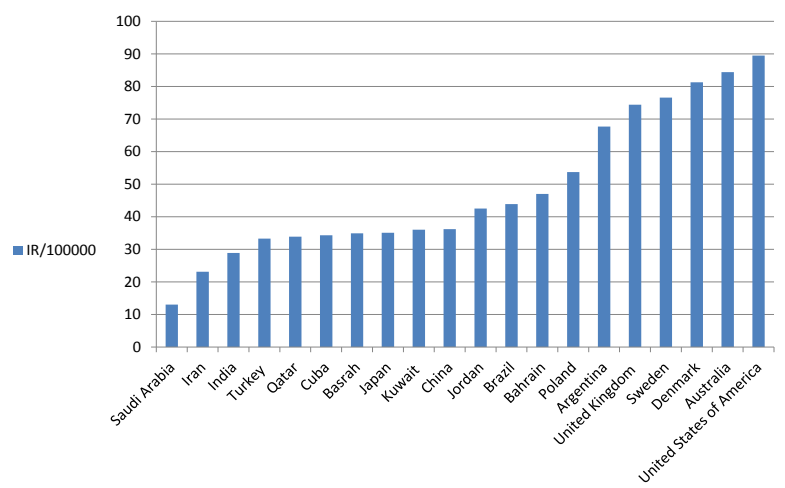

Figure 4 . Comparative Age-Standardized Incidence Rates of Breast Cancer in Selected Countries.

rates of female breast cancer are shown in Table 2. No cases were reported in females aged less than 15 years. Few cases were reported in the age group 15-19 years. Using the age-specific incidence rate, it is clear that the risk of cancer increases sharply with advancing age reaching a peak of 123.8/100,000 females at the age range 50-54 years. A decline in the frequency is noticed from age 65 years and above. Figure 2 illustrates the relative frequency and the age-specific incidence rates. The bulk of new cases occurred in the fifth decade while the peak incidence rate was in the sixth decade of age. No clear difference could be seen in the mean age of cases in different years (Figure 3)

\section{Discussion}

Breast cancer is the top cancer in Iraq and in Basrah according to all documents available from the incident cancers (Habib et al, 2007, BCRG, 2009, Iraqi Cancer Board, 2012). The risk is high and is increasingly registered. It is also a significant contributor to cancer related mortality in Basrah and southern Iraq (Habib et al, 2007). Such a significant position occupied by breast cancer strongly motivated us to start systematic work to improve detection and registration of new cases and to quantify the extent of the problem. In this paper we are reporting the best epidemiological estimates on incidence rate of breast cancer in Basrah. The data used are reasonably reliable in coverage but problems related to missing cases and denominators cannot be claimed to have been completely avoided. Yet, intensive efforts were made to identify every case of breast cancer and to obtain the most accurate possible estimate of the population of
Basrah and its age and sex composition.

Incident breast cancer has occurred in females as early as 17 years and showed a rising trend of risk with advancing age. The highest risk in terms of relative share is seen in the 5 th and the 6 th decades of age while the highest age specific incidence rates are seen in the 6th and first half of the 7 th decades. This pattern of age risk is compatible with the case in many other countries and affirms the fact that breast cancer strike young and middle aged females when the bulk of cases occur (Ferlay et al, 2012).

Regarding whether the current level of breast cancer risk reflects an increase in the disease or not, the answer is not straight forward. The degree of completeness of the data used in the present study cannot be compared with most previously available data. The completeness in data available prior to 2005 is doubtful as many cases could not have been registered. Only one previous study by Al-Badri and Ajeel (1998) on the epidemiology of breast cancer in Basrah could be considered compatible for comparison with the present study. Using the data from the latter, the crude incidence rate of breast cancer in 1995 could be estimated at around 11 per 100,000 females. This rate is much lower than the annual average rate for the years 2005-2012 which is 23.7 per 100,000 females. Thus, taking these two figures on their face value, it is possible to say that the risk of breast cancer based on reported cases has almost doubled within two decade or so. Factors which must be considered in interpretation of such difference may include differential identification and registration, improved diagnostic methods and introduction of screening and early detection tools. But part of the difference is likely to reflect a real increase in breast cancer in Basrah. The rise may be related to a package of risk exposures related to life style, environmental factors and exposure to ionizing radiation from various sources including exposure to depleted uranium (Abdul-Samad et al 2009). No definite conclusion can be drawn about whether breast cancer has increased in Basrah and if so why? The time trend shown over the years 2005-2012 with much more representative data in the present study does not support the view that breast cancer risk has increased dramatically in recent decades. The evidence generated from the present study suggests that breast cancer showed only modest increase during the last ten years. In the meantime, it is difficult to exclude a real change in the risk of cancer without making careful identification and analysis of incident cases during the 1980s and 19990s. Nevertheless, the current incidence rate (crude :23.7/100,000, age-standardized $34.86 / 100,000$ ) is high and justifies intensive efforts to improve early detection of cases, better treatment amenities and long term preventive measures.

Using the age standardized incidence rate as reported in this paper, it is possible to put the risk in Basrah within a regional and international context. The incidence rate in Basrah is higher than rates reported for Oman, United Arab Emirates and Saudi Arabia, very close to rates for Kuwait (Al-Hamdan et al, 2009) but much lower than the high rates in Jordan (Tawarneh,2007), the United states and Britain as described in Table 3. 


\section{References}

Abdul-Samad AA, Al-Kamil EA, Al-Sodani AH (2009). Breast cancer and selected lifestyle variables: a case-control study. Bahrain Medical Bulletin, 31, 1-10.

Al Attar I (2005). Breast cancer: The magnitude of the problem. Egyptian Society of Surgical Oncology Conference. Taba-Sinai 30 March-1 April 2005.

Al-Badri K, Ajeel NA (1998). Study of the risk factor of female breast cancer in Basrah Governorate. Med J Basrah, 16, 21-38.

Al-Hamdan N, Ravichandran K, Al-Sayyad J, Al-Lawatti J, Khazal Z et al (2008). Incidence of cancer in Gulf Cooperation Council Countries, 1998-2001. East Mediterr Health J, 15, 600-11.

Al-Hilfi RA, Habib OS (2015). Incidence of cancer in Basrah: A household survey results. Asian Pac J Cancer Prev, 16, 1163-7.

Al-Hilfi RA, Habib OS (2015). Cancer mortality in Basrah: A household survey results. Med J Basrah, 33, 6-10.

BCRG. Cancer in Basrah: Epidemiological analysis of incident cancer 2005-2008.Basrah Cancer Research Group. Dar Al-Kutub for Publication, 2009. Aversion is also available on www.basmedcol.com

Farina AR , Mackay AR (2014). Gelatinase MMP-9 in tumor pathogenesis and progression. Cancer, 6, 240-96 .

Ferlay J, Soerjomataram I, Ervik M, et al. GLOBOCAN 2012, Cancer incidence and mortality worldwide: IARC, Lyon, France. International Agency for Research on Cancer; 2013. Available from: http://globocan.iarc.fr,

Habib OS, Al-Ali JK, Al-Wiswasi MK, et al (2007). Cancer Registration in Basrah 2005. Preliminary results. Asian Pac J Cancer Prev, 8, 187-90.

Habib OS, Essa SS, Khalaf SA, Zuaiter HT (2007). Cancer mortality in Southern Iraq. Marsh Bulletin, 2, 110-18.

Habib OS, Al-Diab JMA, Mohsin A, et al (2010). Experience and outcome of population-based cancer registration in Basrah-Southern Iraq in four years (2005-2008). Asian Pac J Cancer Prev, 11, 51-4.

Iraqi Cancer Board (2012). Cancer Registry reports for the years 2004-2010. Ministry of Health, Baghdad.

MoP. Iraqi Ministry of Planning, Central Statistical Organization. Statistic of Men and Women. Iraq.2013.

Parkin DM, Bray T, Ferlay J, Pisani P (2005). Global Cancer Statistics 2002. CA Cancer J. Clin, 55, 74-108.

Tawarneh M, Nimri O (2007). Cancer incidence in Jordan. Jordan, Ministry of Health.

Tuncer AM (ed.). Cancer Report (2010). Asian Pacific Organization for Cancer Prevention.(APOCP). New Hope in Health, Ankara. Pp. 299, 324, 378, 391. 